\title{
The Effect of a Cognitive Behavioral Counseling Program to Suicide Tendencies
}

\author{
DU'AA KHALID TAQI, Assist. Prof. Dr. EMAN ABDULKAREEM AL-TAA'I \\ College of Basic Education - Al-Mustansiriya University
}

DOI: $10.37648 /$ ijrssh.v10i04.044

Received:10 ${ }^{\text {th }}$ August, 2020; Accepted:18 ${ }^{\text {th }}$ September, 2020; Published: 26th December, 2020

\begin{abstract}
A The aim of this research is to identify suicidal tendencies and the effect of the psychological counseling program in reducing suicidal tendencies among students of the fifth year of middle school in Baghdad governorate. The research consisted of (400) students of the fifth preparatory phase in the districts of Rusafa A and al-Karkh 1. The research included (32) female students who were randomly selected, and the researcher used the experimental method, and the results found that there was suicide among fifth-grade middle school students. The research also found that the designed program has a high effectiveness in reducing suicide among the research sample.and in favor of the social level, and in the light of the findings of the researcher presented a number of recommendations and suggestions.
\end{abstract}

\section{PROBLEM THE RESEARCH}

The love of survival is an instinct in man, and the desire for life is a rule and therefore the desire to die must be an exception. Therefore, it is natural for some people to have a tendency to commit suicide until the exception of the rule is proven (Jacob, 1984, p.91). As for this exception, it becomes a widespread phenomenon. The matter requires a serious scientific study to identify the causes of this spread. Life is the most valuable thing we have and preserving it is a goal that gives a person a sense of the importance of his presence on this earth, and when death kidnaps an individual, it is considered a very natural thing, but for a person to sign his death certificate, that is the mystery that leaves A lump in the soul and many questions, hence the problem of the current research arose. Thinking about suicide indicates that there is a tragedy that human beings go through every day. Some of them have become unable to see a glimmer of hope in life, and that the only solution to get out of this darkness is death itself .( Al-Afifi, 1990, p. 89)

The topic of suicide has become a wide range of researchers specializing in various fields such as medicine, sociology, law, and psychology. This increased interest is due to the fact that the phenomenon is a social and personal problem with serious consequences that indicate on the one hand a disorder of personality and disturbance of its health, and also on the other side it indicates an imbalance in the social environment.

The seriousness of the problem is evident in the doubling of suicide rates, whether at the global level or at the local level. The World Health Organization (WHO) specialists believe that the number of those who kill themselves unnecessarily has reached high levels, as there is an average of about 3000 people who commit suicide every day. Thirty minutes do not pass without witnessing a person committing suicide and destroying the lives of his family and friends. For every person who commits suicide there is 20 or more other people who attempt suicide 
(Saxena, 2007, p.95). The current research problem can be identified by answering the following question (Does the cognitive-behavioral counseling program have an effect on fifth-grade middle school students...??)

\section{THE IMPORTANCE OF THE RESEARCH}

The importance of studying suicide is because it represents the summit of the tragedy on the stage of life, in which the hero of the scene is the killer and the murderer at the same time, and the strangest thing in the scene is the moment of the implementation of the suicide decision, that moment that represents the climax of the human tragedy when a person voluntarily chooses with his free will to leave life after losing all Hope in it, because human societies reject the option of suicide as a solution to the crisis of human existence (Jaradat, 2015, p. 1). Al-Otaibi study (2004) indicated that the main reason for suicide is lack of faith, despondency and despair from the mercy of God, as well as some social and economic reasons. Emotional, academic and psychological diseases such as psychological diseases (Al-Otaibi, 2004, p. 122). On the other hand, its spread in an important age stage, which is the intermediate stage of adolescence, which represents the stage of middle school because it is an accurate and decisive stage from the psychological and social point of view, and it is a watershed stage in the life of the student, as it qualifies for entry to the university stage, which results in exposure to a huge amount of Psychological pressures that we may not be able to bear its brunt. If we think about the difficult cases in which we wish our lives would stop, we would see that these are the same reasons that bring people complaining about the suicide attempt. There is one big difference, of course, is that suicidal thoughts for most of us pass Quickly, it is just a reaction to a painful incident, and most of us address the issue after talking about it to a friend or a relative, or find a solution to its problems, so suicidal thoughts appear automatically. However, these thoughts and suicidal plans remain for some of us and take root and are associated with psychological disorders and severe life difficulties, including for example Example: Feeling hopeless, frustrated, losing interest in life and losing hope in the future. Adolescents may think of suicide when they fail in school or quarrel with their parents at home, or else Females are more prone to depression and social pressure. Therefore, their suicide probability is greater until the risk of death as a result of suicide is higher for men usually and the reason for this is because men may choose more dangerous suicide methods and we should take all suicide attempts seriously, whether for men or women. (Patel, 2008, pp. 63-64), From here comes the role of psychological counseling, as it is the process of guiding the guides to understand their potentials, abilities and preparations, and to use them in solving their psychological problems and crises, define their goals and develop plans for their future lives through their understanding of their reality and present, and help them achieve the greatest amount of happiness and sufficiency (Al-Dahri, 2011, p.19) Munre (1979) stressed the importance of counseling because it is believed that individuals have basic needs that they can only achieve through counseling(Al-Razzaq, 2009, p. 13)

\section{AIMS OF THE RESEARCH}

Recognizing the effect of cognitive-behavioral counseling in reducing suicidal tendencies among fifth year middle school students

To achieve this goal, the researcher will verify the following hypotheses

1- There are no statistically significant differences at the level of significance $(0.05)$ between the average scores of the experimental group members in the pre and post test on the suicidal tendency scale after applying the cognitive behavioral counseling program.

2-There are no statistically significant differences at the level of significance $(0.05)$ between the average scores of the control group in the pretest and the post test on the suicidal tendency scale after applying the cognitive behavioral counseling program to the members of the experimental group.

3-There are no statistically significant differences at the level of significance $(0.05)$ between the average ranks of the scores of the members of the experimental group and the control group from the post-test on the scale of suicidal tendencies after applying the cognitive behavioral counseling program.

4-There are no statistically significant differences at the level of significance (0.05) between the mean scores of the students of the experimental and control groups on the scale of suicidal tendencies in the target test due to the group variable (experimental, control). 


\section{RESEARCH LIMITS}

The current research is determined by identifying the suicidal tendencies of fifth-year middle school students in Baghdad governorate in the two education departments of (Rusafa Al-Awal) (Al-Karkh Al-Aula) for the morning study for the academic year (2019-2020)

\section{DEFINITION OF TERMS}

\section{1- Impact: It was defined by Ibn Manzur linguistically:}

(It is the rest of the thing in a thing) and the plural is an effect and an effect, and it came out in its trace, that is, I traced its effect and the effect in the movement, what remained of the object's drawing (Ibn Manzur, 1983, p. 19).

2- The mentoring program: defined by Murray (1970)

As a series or group of operations or activities that should be carried out to achieve certain goals, and the goal of the program is to organize the relationship between the goals of the plan and its project and its implementation (Murary 3: 1970).

\section{3- Cognitive-Behavioral Coaching: Known by Albert} Alice (1977)

It is the way to modify false and illogical ideas based on subjective expectations, and on a mixture of speculation, exaggeration, and exaggeration to a degree that does not coincide with the actual potential of the individual (Alloush, Zaghboush, 2009, p.61).

4- suicidal tendencies: defined by Aaron Beck (2002)

Aaron Beck (2002): The individual's tendency to accept wrong ideas and beliefs about himself for the ultimate expression of the desire to flee, as he sees that his future is burdened with pain and suffering and does not find the way to relieve his suffering to reduce his situation and considers it the end of his misery and misery, so he sees death as more delicious than life (Beck, 2002, p. 101).

Theoretical definition: Since the two researchers have adopted Beck's point of view to define the concept of suicidal tendencies, the theoretical definition adopted by the two researchers is the same definition referred to as Beck.
Procedural definition: The total score obtained by the respondent by answering the paragraphs of the scale of suicidal tendencies prepared in the current research.

\section{CHAPTER TWO THEORETICAL FRAMEWORK}

\section{ARON BECK THEORY}

Beck's theory is one of the theories that gave a clear and comprehensive explanation of the concept of suicide, and at the same time he developed an approach known as cognitive therapy (CT) as a result of his research on depression and Beck's observation about psychological problems showed that they have a negative stimulus while trying to explain a specific event in life. Which contributed to cognitive distortions and these distortions lead to wrong thinking and then suicide (Curry, 2011, p. 371).

Beck believes that some ideas are characterized by being broad, broad and then extreme, and according to him, people in their lives adhere to laws (with assumptions or equations) and get into trouble when they resort to characterization, interpretation and evaluation based on a set of laws or principles that are not realistic, or when they use these principles in an extreme way. Or inappropriate, and if individuals make a decision or are determined to live according to principles that may lead them to misery, misery, and suicidal thoughts (Curry, 2011, p. 376)

Beck emphasized that any situation consists of several stimuli, except that the individual selects certain features, organizes them into a pattern and perceives them within a certain unit, and from here the manuscript arises. One in different ways according to the variables of situations or circumstances, except that individuals who contemplate suicide fall under the influence of negative scripts tend to be consistent in their perception and response to variables even with different circumstances surrounding the variable each tim (Beck, 2000, 101).

" Beck" believes that the association of suicide with the individual's thinking style, as he sees events through a dark, inflexible tunnel. The outlook of life is horrific and there is no solution but thinking about suicide. The cognitive model in its interpretation of suicidal thinking is also based on the existence of a biased cognitive system resulting from wrong processes in thinking. The processing of information, and the existence of un- 
adapted cognitive schemes that form the meanings of events in a distorted manner that makes life unbearable. However, the cognitive manuscript in this case explains the automatic tendency of suicidal thinking towards negative interpretations despite the objective evidence that refutes them. Therefore, suicidal thinking and the motive for suicide is Distorted thinking is more than a disturbance of conscience (Beck, 2000, p.70).

\section{PREVIOUS STUDIES}

\section{A Study of Ali (2011)}

Title: Suicidal tendencies and their relationship to emotional equilibrium among adolescents from the middle school students in Garmian. Objective: To identify the nature of the relationship between suicidal tendencies and emotional equilibrium. Sample: middle school students in the Garmian region, whose number is $(18,107)$ students.

Tools: a tool for measuring suicidal tendencies and a tool for measuring emotional balance.

Results: The absence of differences in suicidal tendencies according to the gender variable (males and females), the absence of differences in emotional balance according to the gender variable (males and females), and the inverse relationship between suicidal tendencies and emotional balance. The higher the suicidal tendencies, the emotional balance is low and vice versa. the correct (Ali, 2011, p. 134).

\section{Aoshia (2017)}

Title: Suicidal Tendency and Lifestyle Factors for High School Students in Miyazaki City.

Objective: To identify the relationship between suicidal tendencies and lifestyle of high school students.

The sample:213 male and270 female students, aged between (12-15).

Tools: Suicide Propensity Scale and Self-Enhancement Scale for Lifestyle Traits and Features.

Results: a gender difference in suicidal tendency, which was strongest among female students, and a relationship between suicidal tendency and lifestyle of high school students (Aoshia, 2017, p7).

\section{CHAPTER III: PROCEDURES OF THE RESEARCH}

\section{The Research Method}

The two researchers will use the approach in the quasiexperimental method to suit the research objectives

\section{First: the research community}

The research community included the fifth year middle school students, and their number was (400) students.

\section{The research sample}

The sample of the study consisted of (32) female students divided into two groups: the control group, who were (16) students, and the experimental group, whose number was (16) students.

\section{Search tool}

The study tool included the suicide scale and the cognitive-behavioral counseling program as follows:

1- suicide tendencies scale

Scale description-

After the two researchers reviewed the literature, sources, and previous studies related to the research variable, which are represented by the Maousha scale (2008), the Ali scale (2011), and the Sultani scale (2014), it became clear that the scales that were viewed were for samples different from the current research sample. The two researchers built the measure of suicidal tendencies on the basis of the current research sample, following the following steps:

The information gathering tool consists of two parts in its final form

The first section: Initial information about the study sample members, then it dealt with the desired variables to be studied related to suicide (age, father's achievement, mother's achievement, intelligence).

The second section: It contains 48 paragraphs, which are the dimensions of the suicide scale .

\section{Scale correction}

In front of each paragraph of suicidal tendencies, the researcher placed five graded alternatives to the answer that are applicable to me in a degree (always, often, sometimes, rarely, never) and according to the correction key that refers to giving the grade (5) to the first alternative (always), and the degree (4) For the second 
alternative (often), the score (3) for the third alternative (sometimes), the score (2) for the fourth alternative (rarely), and the score (1) for the fifth alternative (never)

\section{Standard (psychometric) properties of the scale}

The researcher verified the psychometric properties of the scale through several indicators, namely:

\section{First: Validity of the Scale}

The validity of the test is one of the important and necessary characteristics that the specialists are keen to have during the construction of the test. It is the most important characteristic of a good )Al-Naimi, 2014,p 219( test

For the current scale, two indicators of honesty have been extracted, which are the apparent truthfulness and sincerity of construction. The following is an explanation of how to verify each of them:

Table(1)

\section{A- Content Validity}

It is the general appearance of the scale or its external image in terms of the type of vocabulary, how it is formulated, and the extent of its clarity, and this type of validity indicates the extent to which the questionnaire fits the hypotheses that were put to measure it

(AGA, 2002, p. 122)

The researcher verified the apparent validity of the suicidal tendencies scale when she presented the paragraphs of the suicidal tendencies scale, consisting of six domains containing (48) paragraphs, in its initial form, to a group of (21) experts in the science of psychological counseling, measurement and evaluation, and taking their opinions and to verify the validity and accuracy of all The field and its paragraphs in representing suicidal tendencies among fifth-year middle school students, and the result was the acceptance of all the paragraphs, which are (48) paragraphs, as it received the approval of the experts by (80)\% or more, as the researcher adopted this percentage of expert approval as a criterion for the validity of the field and its paragraphs in representing suicidal tendencies.

$\mathrm{Ka}-2$ test resuits for expert opinions about the validity of the scale items.

\begin{tabular}{|c|c|c|c|c|c|c|c|}
\hline component & The paragraphs & Experts & Arrested & $\begin{array}{l}\text { We do } \\
\text { not } \\
\text { accpet }\end{array}$ & $\begin{array}{ll}\text { computed } & k a-2 \\
\text { value } & \end{array}$ & $\begin{array}{l}\text { Tabular } \\
\text { ka-2 value }\end{array}$ & $\begin{array}{l}\text { Indication level } \\
(0,05)\end{array}$ \\
\hline \multirow{2}{*}{ frustration } & 8، 7، 6، 4، 2، 1 & 20 & 18 & 2 & 12,8 & \multirow{2}{*}{3,84} & function \\
\hline & $3 \cdot 5$ & 20 & 16 & 4 & 7,2 & & function \\
\hline \multirow{2}{*}{ aggressiveness } & ، 13، 12، 16، 16 15 ' 15 ' & 20 & 20 & 0 & 20 & \multirow{2}{*}{3,84} & function \\
\hline & $8 ، 9$ & 20 & 17 & 3 & 9,8 & & function \\
\hline \multirow{2}{*}{ Feeling guilty } & 22، 20، 19، 17 & 20 & 20 & 0 & 20 & \multirow{2}{*}{3,84} & function \\
\hline & 24، 23، 21، 1 & 20 & 19 & 1 & 16,2 & & function \\
\hline \multirow{2}{*}{$\begin{array}{l}\text { How much self- } \\
\text { efficy }\end{array}$} & $\begin{array}{l}26 \text { ، } 27 \text { ، } 30 \text { ، } \\
32\end{array}$ & 20 & 17 & 3 & 9,8 & \multirow{2}{*}{3,84} & function \\
\hline & 25 28، 31 & 20 & 16 & 4 & 7,2 & & function \\
\hline \multirow{2}{*}{$\begin{array}{l}\text { Inability to self- } \\
\text { control }\end{array}$} & $\begin{array}{l}33 ، 34 ، 35 ، ~ \\
38 ، 40\end{array}$ & 20 & 18 & 2 & 12,8 & \multirow{2}{*}{3,84} & function \\
\hline & 37 ، 39 & 20 & 15 & 5 & 5 & & function \\
\hline
\end{tabular}




\begin{tabular}{|c|c|c|c|c|c|c|c|}
\hline $\begin{array}{l}\text { Feeling } \\
\text { miserable and }\end{array}$ & $\begin{array}{l}\text { ، 45، 43، 42، } 47 \\
46 \text { 46 }\end{array}$ & 20 & 20 & 0 & 20 & 3,84 & function \\
\hline \multirow{2}{*}{ sad } & 8، 7، 6، 4، 2، 1 & 20 & 19 & 1 & 16,2 & & function \\
\hline & $3 ، 5$ & 20 & 18 & 2 & 12,8 & & function \\
\hline
\end{tabular}

From the table it becomes clear that approval was obtained for the validity of (48) items in measuring what they were set for, which will be analyzed statistically to calculate some statistical indicators.

\section{B- Constrcut Validity}

It is intended to analyze the degree of the scale based on the psychological structure of the characteristic to be measured or in light of a specific psychological concept (Cronbach, 1964, p: 120) and it is called logical truthfulness or content and it deals with the paragraphs of the scale and their contents in terms of their arrangement and the number of their representation of the aspects required to be well represented, and it means creating a relationship Between the results of the scale and the characteristic that the scale aims to measure (Abbas, 2014, 262), the researcher verified the validity of the construct through the distinction by finding differences between groups and individuals, the relationship of the paragraph to the total degree, the relationship of the paragraph to the field to which it belongs, and the matrix of internal correlations for the independence of the sub-scales. In order to identify the extent of the independence of the subscales in measuring the concept of suicidal tendencies, and then find the internal correlation coefficients between the overall scores of the sub-scales.

\section{Second: Scales Reliability}

Consistency is considered one of the basic concepts in psychological and educational measurement, and the tool must be fixed for its suitability for application. It is intended for consistency in the results of the scale. Time
(Spring, 2009, p. 111), and to verify the stability of the current scale, the reliability was calculated by the two methods of retesting and Vackronbach.

\section{Test-retest method}

It is also called the External Consistency Coefficient This method is based on the process of calculating the correlation between the scores of a group of individuals of the stability sample on the test when it is applied and re-applied after a period of time has passed since the first application, and thus this type of transactions reveals the degree of stability of the characteristic measured during this period(Odeh,2002,34)

Calculating stability in this way, which is called the stability factor over time, requires re-applying the scale to the same stability sample with a time difference on a sample of female students consisting of (100) female students of the fifth grade of middle school, drawn randomly from the sample of statistical analysis of (400) students. The difference between the two applications was (15) days, and specialists in psychometrics indicate that the appropriate time period between the two applications should not be less than (14) days, and after the completion of the application, the stability of the suicidal tendency scale was calculated by calculating the scores of this sample with its scores in the first application and using a correlation coefficient. "Person Correlation" between the scores of the two applications, as the value of the reliability coefficient was $(0.82)$, which is a good reliability coefficient.

\section{Table(2)}

\begin{tabular}{|l|l|}
\hline Method of extracting firmness & The value of the correlation coefficient \\
\hline Method for retesting & $\mathbf{0 , 8 2}$ \\
\hline Alfa- Cronbach & $\mathbf{0 , 8 0}$ \\
\hline
\end{tabular}




\section{2- Cognitive behavioral program}

With the aim of investigating the effect of a cognitivebehavioral counseling program to reduce suicide among fifth-grade middle school students, the researcher selected (32) students who were distributed into two groups, each group consisting of (16) students.

The researcher built a cognitive behavioral counseling program consisting of (10) sessions, each session lasting (45) minutes.

\section{Program Goals:}

-The general objective: is to reduce suicidal tendencies among fifth year middle schools tudents .

- Special goals: Through the general objective of the research, the special goals of each counseling session were derived that correspond to the title of the session, and lead to the achievement of the general goal of the counseling program, which is to reduce the suicidal tendencies of the fifth year middle school students.

\section{The foundations of building the extension program}

The indicative program is based on several foundations for the success of the program.

1- Taking into consideration the type and nature of the problem and setting goals in light of the techniques that are used for the problem

2- The guide must take into account the individual differences of each member of the counseling group

3- The chronological age of the people participating in the program, the environment in which the individual lives, and the age stages

4- The realism of the program, the possibility of implementation, the extent of benefit from it, and the generalization of the results to others

( Al-Zoghbi, 2013, p. 333)

\section{The instructional methods used in the extension} program:

1- Identify the thoughts related to maladaptatio

The emotional responses, motives, and apparent behavior are guided by the thought and are guided by it. A person may be completely unaware of automatic thoughts that greatly affect their behavior, feelings, and enjoyment of their experiences. However, with some training, he can increase his awareness of these ideas and identify them with a high degree of consistency and consistency (Beck, 2000, p. 189).

\section{2- Fill in the blanks method}

When patients talk about events and their reactions to these events, there is a gap between the stimulus and the response, and this gap is represented in the ideas and beliefs, and the therapist should explain to the patient the illogicality of his ideas because they are not balanced due to neglecting some things that are important to address In order for the therapist to diagnose the symptoms and then find the appropriate treatment formula, the therapist's task is to fill the void by teaching the individual to focus on the thoughts and knowledge that occur during the experience of the stimulus and the response (Beck, 1976, p: 239).

\section{3-Documentingconclusions}

Individuals may be able to distinguish between internal mental processes and external stimuli, that they need to learn methods for obtaining accurate information and knowledge, and this includes knowing that the hypothesis is not a realistic fact, and the therapist helps to examine their conclusions and test them with the test of reality and truth, using In that the rules of evidence or scientific evidence ( Patterson, 1990, p. 38)

\section{4- Discussion:}

This technique helps the individual to confront his irrational thoughts and beliefs in a logical manner that he works to implement them following dialectical and educational methods through which he deals with these irrational ideas and beliefs in the various contexts in which they may appear (Buzzou, 2013, p.159).

5- Dimensions and Focus

Beck calls the process by which thoughts are viewed as "dimensional" and it includes the recognition that automatic thoughts are not reality, are not trusted, are harmful to adaptation, and include events outside the individual's frame (Abu Asaad and Oribat, 2015, p. 231).

\section{The topics of the guidance sessions:}

Each session includes the following group counseling program: 
1- Beginning of the session by reviewing previous sessions, except for the first session

2- Discussing homework in the previous session

3- Discussing the topic and goal of the session

4- Application of extension techniques and methods

5- Summarizing and closing the session and giving homework

\section{THE FOURTH CHAPTER}

\section{RESULTS}

The first hypothesis: (There are no statistically significant differences at the level of significance $(0.05)$ between the mean scores of the experimental group students in the pre and post tests on the scale of suicidal tendencies after the application of the counseling program).

To verify the validity of this hypothesis, the researcher used the wilcoxon test to detect the differences between the pre and post measurements with respect to the averages of the degrees of suicidal tendencies for the experimental group, as the calculated Wilcoxon value of (6) was less than the tabular value of (30) when The level of significance (0.05), which means that there are statistically significant differences between the average ranks of the students' scores in the experimental group on the scale of suicidal tendencies in the pretest and the post test, and this difference is in favor of the post test. Therefore, the null hypothesis is rejected which states: (There are no related differences Statistical significance at the level of significance $(0.05)$ between the average ranks of the scores of the students of the experimental group in the pre and post tests on the scale of suicidal tendencies after the application of the counseling program) and the alternative hypothesis is accepted which states that there are statistically significant differences between the mean ranks of the scores of the experimental group students in the two tests Before and after, and Table (3) illustrates the results related to this hypothesis.

Table(3)

Explains the significance of the differences between the means of measurements of the pre and post measurements for the members of the experimental group on the scale of suicidal tendencies

\begin{tabular}{|c|c|c|c|c|c|c|c|c|}
\hline \multirow[t]{2}{*}{ Variable } & \multirow[t]{2}{*}{ Ranks } & \multirow{2}{*}{$\begin{array}{l}\text { The } \\
\text { number }\end{array}$} & \multirow{2}{*}{$\begin{array}{l}\text { Mtwst } \\
\text { alratb }\end{array}$} & \multirow{2}{*}{$\begin{array}{l}\text { Majmue } \\
\text { alratb }\end{array}$} & \multicolumn{2}{|c|}{ Rate walkoxon } & \multirow{2}{*}{$\begin{array}{l}\text { The level of } \\
\text { significanc } \\
\mathrm{e}\end{array}$} & \multirow{2}{*}{$\begin{array}{l}\text { Significance of } \\
\text { differences }\end{array}$} \\
\hline & & & & & Tabular & caiculated & & \\
\hline \multirow{2}{*}{$\begin{array}{l}\text { suicide } \\
\text { tendencies }\end{array}$} & negative & 13 & 10 & 130 & \multirow[t]{2}{*}{6} & \multirow[t]{2}{*}{30} & \multirow[t]{2}{*}{0,05} & \multirow{2}{*}{$\begin{array}{l}\text { Statistical } \\
\text { function }\end{array}$} \\
\hline & positive & 3 & 2 & 6 & & & & \\
\hline
\end{tabular}

Wilcoxen tabular value at significance level (0.05) equals (30)

The second hypothesis: (There are no statistically significant differences at the level of significance (0.05) between the average scores of the control group students in the pre and post tests on the scale of suicidal tendencies after implementing the counseling program).

To verify the validity of this hypothesis, the researcher used the wilcoxon test to detect the differences between the pre and post measurements. The calculated Wilcoxon value of (35.50) is greater than the tabular value of (30) at the level of significance (0.05), which This means that there are no statistically significant differences at the level of significance between the average ranks of the scores of the students of the control group in the pre and post tests on the scale of suicidal tendencies. Therefore, the null hypothesis is accepted which states that there are no statistically significant differences between the average grades of the control group students in the pre and post tests And rejects the alternative hypothesis, which states that there are statistically significant differences between the average ranks of the control group students 'scores in the pre and post tests. Table (4) illustrates the results related to this hypothesis. 
Table(4)

The significance of the differences between the means of the pre and post measurements of the control group members on the scale of suicidal tendencies

\begin{tabular}{|c|c|c|c|c|c|c|c|c|}
\hline \multirow[t]{2}{*}{ Variable } & \multirow[t]{2}{*}{ Ranks } & \multirow{2}{*}{$\begin{array}{l}\text { The } \\
\text { number }\end{array}$} & \multirow{2}{*}{$\begin{array}{l}\text { Mtwst } \\
\text { alratb }\end{array}$} & \multirow{2}{*}{$\begin{array}{l}\text { Majmue } \\
\text { alratb }\end{array}$} & \multicolumn{2}{|c|}{ Rate walkoxon } & \multirow{2}{*}{$\begin{array}{l}\text { The level of } \\
\text { significanc } \\
\text { e }\end{array}$} & \multirow{2}{*}{$\begin{array}{l}\text { Significance of } \\
\text { differences }\end{array}$} \\
\hline & & & & & Tabular & caiculated & & \\
\hline \multirow{2}{*}{$\begin{array}{l}\text { suicide } \\
\text { tendencies }\end{array}$} & negative & 8 & 6,94 & 55,50 & \multirow[b]{2}{*}{30} & \multirow{2}{*}{35,50} & \multirow[b]{2}{*}{0,05} & \multirow{2}{*}{$\begin{array}{l}\text { Is not Statistical } \\
\text { function }\end{array}$} \\
\hline & positive & 5 & 7,10 & 35,50 & & & & \\
\hline
\end{tabular}

Wilcoxen tabular value at significance level (0.05) equals (30)

The third hypothesis: (There are no statistically significant differences at the level of significance (0.05) between the average ranks of the scores of the experimental group students and the average ranks of the scores of the students of the control group on the dimensionless suicidal tendency scale after implementing the program).

To verify the validity of the hypothesis, the researcher used the Mann-Watney test for the independent samples and that the calculated Mann-Whitney value of (16.50) is less than the tabular value of (75) at a significance level (0.05), which means that there are statistically significant differences between The average grades of the experimental group students 'scores and the average grades of the control group's students' scores on the suicidal tendencies scale in the post-test. This is in favor of the experimental group. Therefore, the null hypothesis is rejected which states that there are no statistically significant differences between the average grades of the experimental group students and the average grades of the control group's students The alternative hypothesis is accepted, which states that there are statistically significant differences between the average ranks of the grades of the experimental group students and the average ranks of the scores of the students of the control group in the dimension test, and Table (5) illustrates that:

Table(5)

Average ranks and calculated and tabulated MANN value

Degrees of suicidal tendencies afterwards

\begin{tabular}{|c|c|c|c|c|c|c|c|}
\hline \multirow[t]{2}{*}{ The group } & \multirow[t]{2}{*}{$\begin{array}{l}\text { The } \\
\text { number }\end{array}$} & \multirow[t]{2}{*}{$\begin{array}{l}\text { Mtwst } \\
\text { alratb }\end{array}$} & \multirow[t]{2}{*}{$\begin{array}{l}\text { Majmue } \\
\text { alratb }\end{array}$} & $\begin{array}{l}\text { The valu } \\
\text { whitney }\end{array}$ & of mann & \multirow[t]{2}{*}{$\begin{array}{l}\text { The level of } \\
\text { significance }\end{array}$} & \multirow[t]{2}{*}{$\begin{array}{l}\text { Indication } \\
\text { at the level }\end{array}$} \\
\hline & & & & caiculated & Tabular & & \\
\hline Experimental & 16 & 9,53 & 152,50 & \multirow{2}{*}{\multicolumn{2}{|c|}{75}} & \multirow[t]{2}{*}{0.05} & \multirow[t]{2}{*}{$\begin{array}{l}\text { Statistical } \\
\text { function }\end{array}$} \\
\hline The officer & 16 & 23,47 & 375,50 & & & & \\
\hline
\end{tabular}

The Mann - WTNI tabular value at the level of significance (0.05) equals (75)

The fourth hypothesis (there are no statistically significant differences in the effect of a cognitive-behavioral heuristic program caused by the independent variable in the level of the dependent variable in).

- The pre and post tests of the experimental group on suicidal tendencies .

- Post-test for the experimental and control groups on suicidal tendencies .

To achieve this, the researcher used Cohen's equation to calculate the effect size for the pre and post tests of the experimental group, and the ETA square equation to calculate the effect size for the post test for the experimental and control groups, as follows: 


\section{Size the effect using Cohen's equation}

It means the difference between the averages of each of the pre and post test of the experimental group of the variable of suicidal tendencies divided by the weighted standard deviation, and knowing the size of the effect helps us to determine the amount of the relative effect of the pilot program, and to determine the level of the effect, Cohen's equation was applied and there is a criterion for the size of the effect where:

The effect is simple: 0,20

The effect is moderate: 0.50

The effect is large: 0,80

And after extracting the arithmetic mean and standard deviation for the pre and post tests and the weighted standard deviation as shown in Table (6)

Table(6)

The arithmetic mean and standard deviation for the pre and post tests

\begin{tabular}{|l|l|l|l|}
\hline The test & SMA & Std.deviation & Weighted deviation \\
\hline Tribal & 154,875 & 8,065 & 9,708 \\
\cline { 1 - 3 } Dimensional & 133,500 & 11,111 & \\
\hline
\end{tabular}

After the application of Cohen's equation, the size of the effect was $(2,201)$. Therefore, the size of the effect of the counseling program in reducing suicidal tendencies has a significant effect for the experimental group.

In light of the results of the current research mechanism, the researcher recommends the following:

1- Using the current scale in diagnosing suicidal tendencies

2- Disseminating the application of the counseling program that the current research relied on educational counselors in order to reduce suicidal tendencies among middle school students by the educational counseling department in the General Education Directorate.

3- Conducting a study aimed at identifying the relationship between suicidal tendencies and between psychological, social, demographic and economic variables in Iraqi society.

4- Holding a workshop and raising this issue boldly with schools and universities, in front of the media and informing citizens of its results.

\section{REFERENCES}

1- Abu Asaad, Riyadh, Arabiyat, Ahmad Abdel Halim, (2015), Theories of Psychological and Educational Guidance, 3rd Edition, Dar Al-Masirah for Publishing and Distribution, Amman.

2- Al-Naimi, Muhannad Muhammad Abd al-Sattar (2014): Psychometrics in Education and Psychology, 1st Edition, Central Press, Diyala University, Iraq.

3- Patterson, (1990), Theories of Counseling and Psychotherapy, translated by Hamed Abdul-Aziz Al-Feki, V2, Dar AlQalam Publishing and Distribution, Kuwait.

4- Patel, Vikram (2008) Book of Community Mental Health, 1st Edition, Arab Resources Publishing and Distribution House, Beirut, Lebanon.

5- Beck, Aaron (2000), Cognitive Therapy and Emotional Disorders, translated by Adel Mustafa, Dar Al-Horizon Al-Arabia, Cairo.

6- Al-Jaradat, Nisreen Issa Suleiman (2015), Suicidal Ideas and their Relationship to Risk Factors Associated with Anxiety and Depression in Youth in Palestinian Society, Master Thesis, Al-Quds University, Palestine. 
7- Al-Dahri, Saleh Hasan (2011): Counseling Psychology, Its Theories and Modern Methods, Wael Publishing House, First Edition, Amman, Jordan

8- Abbas, Muhammad Khalil and Nawfal, Muhammad Bakr and Al-Abassi, Muhammad Mustafa and others (2014), Introduction to Research Methods in Education and Psychology, 5th Edition, Dar Al Masirah for Publishing and Distribution, Amman

9- Abdul Razzaq, Mahmoud Shaker. (2009). The effect of two heuristic methods (psychological engineering and selfevaluation) on developing moral intelligence among elementary school students, unpublished (PhD) thesis, College of Education, Al-Mustansiriya University, Iraq.

10- Abdul Razzaq, Mahmoud Shaker. (2009). The effect of two heuristic methods (psychological engineering and selfevaluation) on developing moral intelligence among elementary school students, unpublished (PhD) thesis, College of Education, Al-Mustansiriya University, Iraq.

11- Abdullah, Muhammad Qasim (2010), Theories of Counseling and Psychotherapy, Dar Al-Fikr for Publishing and Distribution, Aleppo, Syria.

12- Al-Otaibi, Mohamed Zayed (2004) Skills of Theater Inspection The Suicide Accident "A Study on Some Suicides in the City of Riyadh", Unpublished Master Thesis, College of Graduate Studies, Department of Police Sciences, Naif Arab University for Security Sciences, Saudi Arabia

13- Al-Afifi, Abdel Hakim (1990), Depression and Suicide (An Analytical Social Study), Lebanese Egyptian Publishing House, Cairo.

14- Ali, Sami Ali (2011), Suicidal tendencies and their relationship to emotional equilibrium among adolescents from middle school students in Garmian District, Sulaymaniyah, Iraq.

15- Odeh, Ahmad Suleiman and Al-Khalili, Khalil Yusef (2002): Measurement and Evaluation in the Educational Process, Amman, Jordan

16- Corrie, Gerald (2011), Theory and Practice in Counseling and Psychotherapy, translated by Dr. Sameh Wadih AlKhafash, Dar Al-Fikr for Publishing and Distribution, Ama-Ali, Sami Ali (2011), Suicidal tendencies and their relationship to emotional balance among adolescents from middle school students in Garmian District, Sulaymaniyah, Iraq.

17- Yaqoub, Saeed Hafez (1984) Depression, a study in psychological depression, first edition, Modernity House, Beirut, Lebanon.

18- Saxena. S. (2007), Suicide in adolescence. American Journal Psychiatry, Vol (149), (94-111.(

19- Aoish, keiko, (2017): suicidal inclination and lifestyle factors in miyazaki city junior high school students, School Health VOL, 13.

20- Cronbach, L. J. (1964). Essentials of psychological testing. New York- printing house, 2nd ed.

21- Beck, A.T., (1976) : Cognitive therapy and the emotional disorders, international universities press, New York. 